\title{
Multilevel optimisation of anaerobic ethyl acetate production in engineered Escherichia coli
}

\author{
Anna C. Bohnenkamp ${ }^{1 *}$, Aleksander J. Kruis ${ }^{1,2+}$, Astrid E. Mars ${ }^{3}$, Rene H. Wijffels ${ }^{1,4}$, John van der Oost ${ }^{2}$, \\ Servé W. M. Kengen ${ }^{2}$ and Ruud A. Weusthuis ${ }^{1 *}$
}

\begin{abstract}
Background: Ethyl acetate is a widely used industrial solvent that is currently produced by chemical conversions from fossil resources. Several yeast species are able to convert sugars to ethyl acetate under aerobic conditions. However, performing ethyl acetate synthesis anaerobically may result in enhanced production efficiency, making the process economically more viable.

Results: We engineered an E. coli strain that is able to convert glucose to ethyl acetate as the main fermentation product under anaerobic conditions. The key enzyme of the pathway is an alcohol acetyltransferase (AAT) that catalyses the formation of ethyl acetate from acetyl-CoA and ethanol. To select a suitable AAT, the ethyl acetate-forming capacities of Atf1 from Saccharomyces cerevisiae, Eat1 from Kluyveromyces marxianus and Eat1 from Wickerhamomyces anomalus were compared. Heterologous expression of the AAT-encoding genes under control of the inducible Lacl/T7 and XyIS/Pm promoters allowed optimisation of their expression levels.
\end{abstract}

Conclusion: Engineering efforts on protein and fermentation level resulted in an E. coli strain that anaerobically produced $42.8 \mathrm{mM}$ (3.8 g/L) ethyl acetate from glucose with an unprecedented efficiency, i.e. $0.48 \mathrm{C}-\mathrm{mol} / \mathrm{C}-\mathrm{mol}$ or $72 \%$ of the maximum pathway yield.

Keywords: Eat1, Anaerobic, Alcohol acetyl transferase (AAT), Escherichia coli, Ethyl acetate, Bioreactor, Fermentation

\section{Background}

Ethyl acetate is used on a large scale as an industrial solvent for the production of paints, coatings and resins [30], as well as in the flavours and fragrances industry [9, 19]. The global production of the ester was estimated at 3.5 million tonnes in 2015 [42]. Currently, ethyl acetate is produced from petrochemicals in energy intensive and unsustainable processes. Traditional Fischer Speier esterification makes use of equilibrium reactions and energy

\footnotetext{
*Correspondence: anna.bohnenkamp@wur.nl; ruud.weuthuis@wur.n ${ }^{\dagger}$ Anna C. Bohnenkamp and Aleksander J. Kruis contributed equally to the work

${ }^{1}$ Bioprocess Engineering, Wageningen University and Research, Droevendaalsesteeg 1, 6708 PB Wageningen, The Netherlands Full list of author information is available at the end of the article
}

used for elevated temperatures and continuous water removal is adding to the costs $[10,24,16]$. A sustainable alternative is the use of biobased processes in which yeasts produce ethyl acetate from sugars or ethanol at high yields $[1,11,26]$. The most prominent and wellstudied yeast is Kluyveromyces marxianus, which produces ethyl acetate from whey sugars at more than $50 \%$ of the maximum pathway yield of $1 \mathrm{~mol}_{\text {ethyl acetate }} / \mathrm{mol}_{\text {glu- }}$ cose $[27,44]$. Other examples include Wickerhamomyces anomalus and Kluyveromyces lactis [17].

Ethyl acetate production in yeast is catalysed by alcohol acetyltransferases (AATs), which synthesise ethyl acetate from acetyl-CoA and ethanol, releasing free CoA in the reaction [19]. The first-described ethyl acetate-producing AAT was the Saccharomyces cerevisiae Alcohol



(c) The Author(s) 2020. This article is licensed under a Creative Commons Attribution 4.0 International License, which permits use, sharing, adaptation, distribution and reproduction in any medium or format, as long as you give appropriate credit to the original author(s) and the source, provide a link to the Creative Commons licence, and indicate if changes were made. The images or other third party material in this article are included in the article's Creative Commons licence, unless indicated otherwise in a credit line to the material. If material is not included in the article's Creative Commons licence and your intended use is not permitted by statutory regulation or exceeds the permitted use, you will need to obtain permission directly from the copyright holder. To view a copy of this licence, visit http://creativeco mmons.org/licenses/by/4.0/. The Creative Commons Public Domain Dedication waiver (http://creativecommons.org/publicdomain/ zero/1.0/) applies to the data made available in this article, unless otherwise stated in a credit line to the data. 
acetyltransferase 1 (Atf1) [33]. However, its homologues in W. anomalus and $K$. marxianus appeared to have only a minor role in bulk ethyl acetate production [17, 25]. Instead, they use the recently identified Ethanol acetyltransferase 1 (Eat1) to produce ethyl acetate [17]. Eat1 is targeted to the mitochondria of yeasts due to the presence of an N-terminal mitochondrial pre-sequence [18]. In yeasts, these pre-sequences are cleaved upon arrival in the mitochondrion by cleavage proteins such as mitochondrial-processing peptidase, Oct1 or Icp55 peptidases $[34,47]$. Only after all processing events have occurred, the proteins fold into their mature and fully functional form. It has recently been shown that the stability of Eat1, when expressed in E. coli, can be improved using N-terminally truncated versions without significantly affecting the specific activity in vitro [20]. An undesirable characteristic of yeast AATs is that they also exhibit thioesterase or esterase side activities, which implies that it is able to hydrolyse acetyl-CoA - the substrate for ethyl acetate production-and also ethyl acetate itself, respectively (Fig. 1). In Eat1, however, these side activities could be subdued by sufficiently high levels of ethanol $[17,35]$.

The production of ethyl acetate from glucose results in an NADH surplus $[6,36,30,28]$. Yeasts are only able to dispose of this surplus by respiration, rendering ethyl acetate production an aerobic process (Fig. 2a). Under these conditions, a significant part of glucose is oxidised in the TCA cycle, leading to lower product yields [50]. Moreover, large-scale aerobic cultivations are often rate limited by the oxygen transfer rate, due to the low solubility of oxygen [13]. Another commonly observed

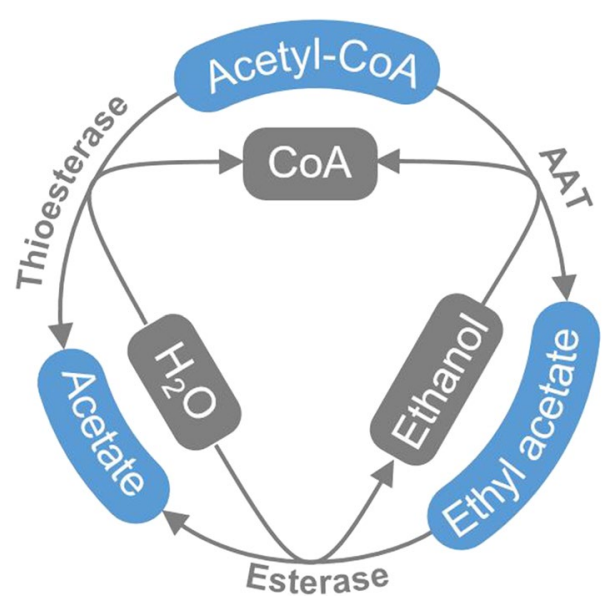

Fig. 1 Schematic representation of the three catalytic activities of the Eat1 enzyme for the case ethyl acetate. The AAT activity of Eat1 catalyses the condensation of acetyl-CoA and ethanol into ethyl acetate, ethyl acetate is degraded into ethanol and water as consequence of esterase activity, and acetyl-CoA is converted into acetate, CoA and water exhibiting thioesterase activity problem in yeast cultivation, particularly in $S$. cerevisiae, is the Crabtree effect, the undesired production of ethanol, consequently lowering the yield on the desired product $[8,27]$. E. coli and other bacteria can avoid this redox imbalance anaerobically using pyruvate formate lyase (Pfl). Instead of forming NADH, the excess redox equivalents are secreted as formate. In the overall pathway, 1 mol glucose is converted via the EMP pathway to 2 mol pyruvate and $2 \mathrm{~mol} \mathrm{NADH}$. Pyruvate is then converted to $2 \mathrm{~mol}$ acetyl-CoA and $2 \mathrm{~mol}$ formate by Pfl. To maintain the cellular redox balance, the 2 mol NADH produced in glycolysis are regenerated by converting $1 \mathrm{~mol}$ acetyl-CoA to ethanol via the bifunctional alcohol/aldehyde dehydrogenase (Adh). A heterologous AAT then condenses the remaining acetyl-CoA with ethanol to form ethyl acetate. This allows redox-neutral production of $0.67 \mathrm{C}-\mathrm{mol}_{\text {ethyl acetate }} / \mathrm{C}$-mol glucose $_{\text {under anaerobic }}$ conditions (Fig. 2b). The only by-product of the pathway is formate which can be further converted to $\mathrm{CO}_{2}$ and hydrogen by formate-hydrogen lyase (Fhl). The latter can also be considered a valuable product that has potential as a biofuel [40]. The resulting anaerobic process requires less energy for cooling and lower stirring rates due to the absence of transfer limitations, and can be upscaled to larger reactor volumes [4].

A critical step in enabling heterologous ethyl acetate production in E. coli is the selection of an efficient AAT catalyst. Both Atf1 and Eat1 have been used to increase ethyl acetate production [38, 17]. AATs from fruit have also been used to evoke ethyl acetate synthesis in E. coli under anaerobic conditions and show various affinities for a range of esters [21-23]. However, these enzymes have not yet been compared in the same metabolic background.

In this study, we optimised anaerobic production of ethyl acetate in Escherichia coli. We compared and evaluated ethyl acetate production by three AATs from different yeasts after reducing the formation of by-products by creating knockout strains. We optimised gene expression levels using two inducible promotors in combination with several inducer concentrations, and also used $\mathrm{N}$-terminally truncated variants. Final experiments in $1.5-\mathrm{L}$ $\mathrm{pH}$-controlled bioreactors with continuous gas stripping resulted in ethyl acetate production at high yield.

\section{Results}

Anaerobic ethyl acetate production in E. coli and reduction of by-product formation

To enable ethyl acetate production in E. coli BW25113 (DE3), we introduced the $K$. marxianus eat1 (Kma eat1) under the control of the IPTG-inducible LacI/T7 promoter. Under anaerobic conditions the strain produced $2.7 \pm 0.1 \mathrm{mM}$ ethyl acetate, representing a yield 

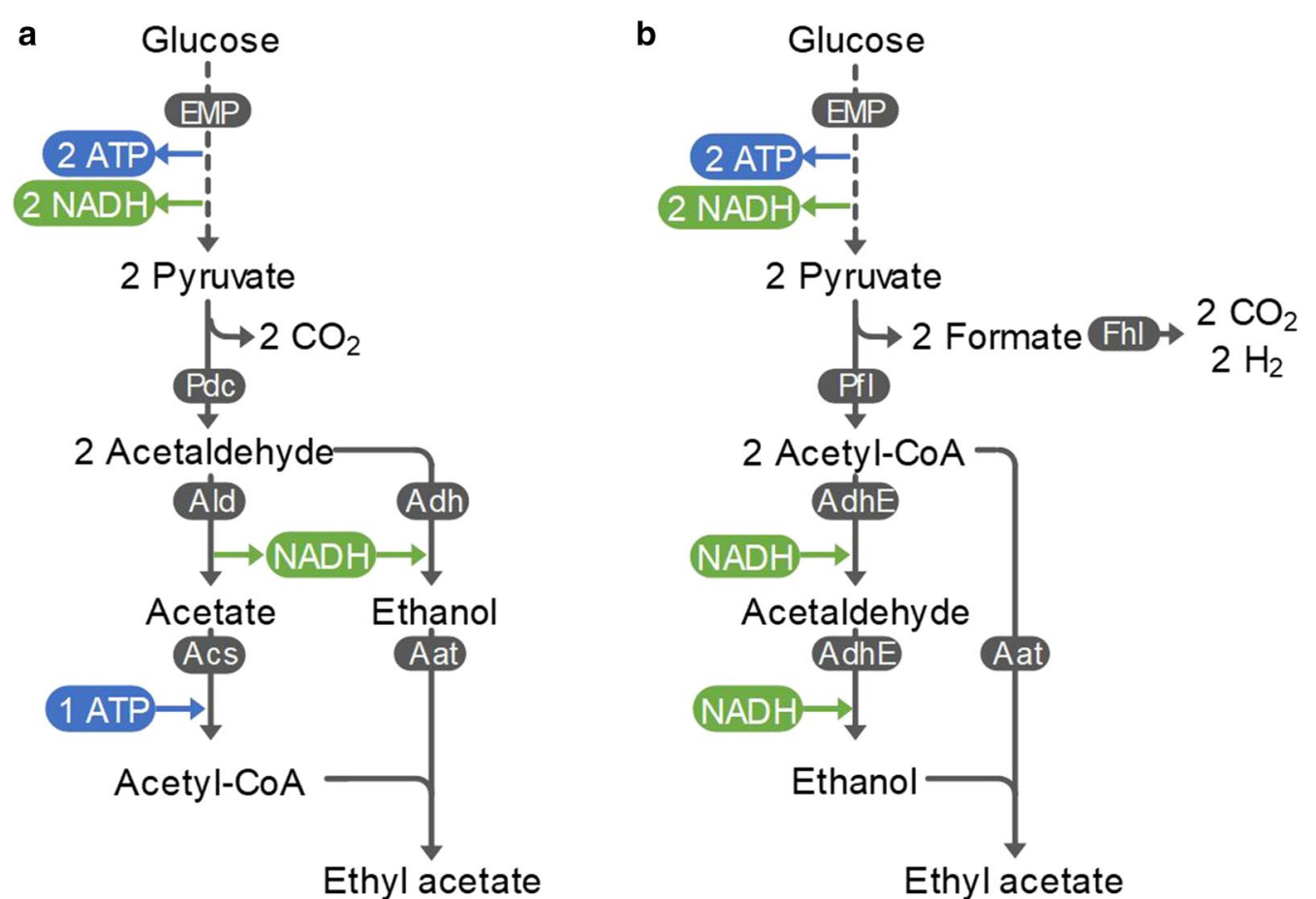

Fig. 2 Two anaerobic variants of ethyl acetate production from glucose via the Embden-Meyerhof-Parnas (EMP) pathway. An alcohol acetyltransferase (AAT) catalyses the production of ethyl acetate from acetyl-CoA and ethanol. a Ethyl acetate production in yeast. Acetyl-CoA is formed in a series of three reactions: pyruvate decarboxylase (Pdc), acetaldehyde dehydrogenase (Ald) and acetyl-CoA synthetase (Acs). Ethanol is formed from acetaldehyde by an alcohol dehydrogenase (Adh). $\mathrm{CO}_{2}$ is produced as a by-product. $\mathbf{b}$ Ethyl acetate production in bacteria (e.g. $E$. coli). Acetyl-CoA is formed directly from pyruvate via pyruvate formate lyase (Pfl). Ethanol is formed from acetyl-CoA via the bifunctional alcohol/ aldehyde dehydrogenase (AdhE). Formate is produced as a by-product that can be converted to $\mathrm{CO}_{2}$ and $\mathrm{H}_{2}$ via formate-hydrogen lyase (Fhl)

of $0.03 \pm 0.00 \mathrm{C}$-mol $\mathrm{m}_{\text {ethyl acetate }} / \mathrm{C}$ - mol $_{\text {glucose }}$ (Fig. 3a, c). Due to the formation of by-products, particularly lactate and acetate, the ethyl acetate titre was low. To maximise the metabolic flux towards ethyl acetate, we disrupted the acetate kinase $(a c k A)$ and lactate dehydrogenase $(l d h A)$ genes to reduce acetate and lactate formation, respectively. This increased the ethyl acetate titre to $9.1 \pm 0.3 \mathrm{mM}$ (Fig. 3b). The final ethyl acetate yield increased to $0.13 \pm 0.00 \mathrm{C}$ - $\mathrm{mol}_{\text {ethyl acetate }} / \mathrm{C}$ - $\mathrm{mol}_{\text {glucose}}$, or $21.4 \%$ of the maximum pathway yield (Fig. 3c). Lactate production was almost completely abolished. Acetate yields did not decrease significantly despite the ack $A$ disruption (Fig. 3c). A possible explanation is that acetate is produced via the hydrolysis of ethyl acetate or acetylCoA by the esterase and thioesterase side activity of eat1, respectively.

Since lactate production can no longer act as sink of $\mathrm{NADH}$, ethanol synthesis should fulfil this role. The conversion of ethanol together with acetyl-CoA to ethyl acetate would basically consume all available NADH and make the entire process redox neutral. However, the accumulation of ethanol and also pyruvate suggests that synthesis of ethyl acetate is limited and that Eat1 activity is the bottleneck of the process (Fig. 3b, c). We therefore focused on optimising the activity of the AAT step.

\section{Selection of ethyl acetate-producing AAT and gene expression optimisation}

We compared the ethyl acetate-production capacity of S. cerevisiae atf1 (Sce atf1), Kma eat1 and W. anomalus eat1 (Wan eat1) genes in E. coli BW25113 $\Delta a c k A \Delta l d h A$ (DE3) cultivated in anaerobic serum bottles. The genes were placed under the control of the inducible LacI/T7 (Fig. $4 \mathrm{a}-\mathrm{c}$ ) or $\mathrm{XylS} / \mathrm{Pm}$ promoter (Fig. $4 \mathrm{~d}-\mathrm{f}$ ) to allow modulation of their expression levels. To induce gene expression, IPTG or $\mathrm{m}$-toluate was added at various concentrations.

Increased AAT activities will reduce the accumulation of pyruvate, increase the production of ethyl acetate when it is active as an AAT, and increase the production of acetate when it is active as either an esterase or thioesterase.

Strains expressing Wan eat1 (Fig. 4b, e) showed the highest ethyl acetate yields compared to the other AAT genes controlled by the same promoter. High yields of ethyl acetate were also reached by strains 

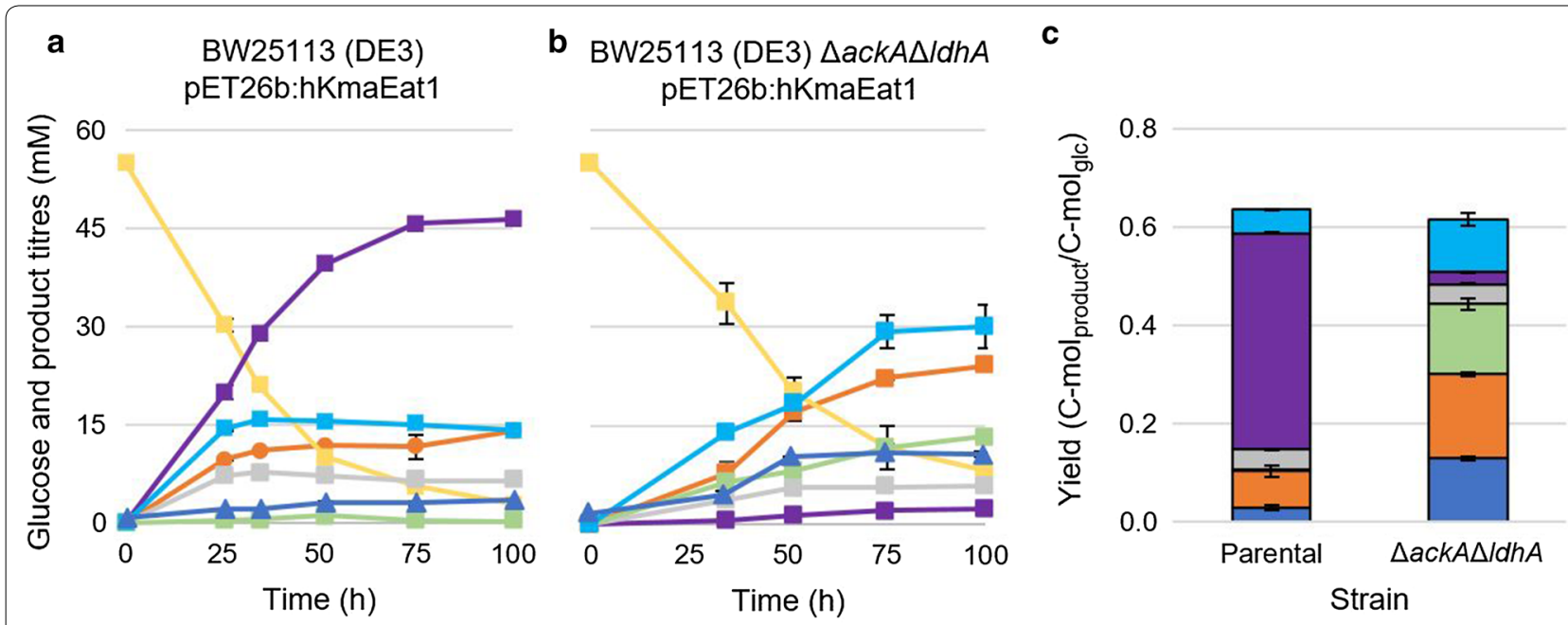

$\square$ Glucose $\Delta$ Ethyl acetate $\square$ Ethanol $\square$ Pyruvate $\square$ Acetate $\square$ Lactate $\square$ Formate

Fig. 3 Anaerobic ethyl acetate production in E. coli BW25113 (DE3) and E. coli BW25113 $\triangle a c k A \triangle / d h A$ expressing the Kma eat1 from pET26b:hKmaEat1. a Fermentation profile of E. coli BW25113 (DE3) (pET26b:hKmaEat1). b Fermentation profile of E. coli BW25113 $\triangle a c k A \triangle l d h A$ (DE3) (pET26b:hKmaEat1). c Product yields during anaerobic ethyl acetate production. Experiments were performed as biological duplicates. Strains were grown in sealed and $\mathrm{N}_{2}$ flushed serum bottles under anaerobic conditions in modified $\mathrm{M} 9$ medium at $30^{\circ} \mathrm{C}$ and $150 \mathrm{rpm}$. Gene expression was induced with $0.05 \mathrm{mM} \mathrm{IPTG}$. Error bars represent the standard deviation. Ethyl acetate concentration in the headspace, $\mathrm{CO}_{2}$ and $\mathrm{H}_{2}$ were not measured

expressing Kma eat1 under control of the lac- T7 promoter (Fig. 4a). Surprisingly, strains expressing Kma eat 1 under the $\mathrm{XylS} / \mathrm{Pm}$ promoter produced only traces of ethyl acetate under all induction levels (Fig. 4d). Sce atf1 also evoked ethyl acetate production, but the yields were significantly lower compared to the two eat 1 genes (Fig. 4c, f). Pyruvate accumulation decreased significantly, indicating that Atf1 was active, but primarily as an esterase/thioesterase as the acetate yields increased. These results show that Eat1 homologues are better catalysts than Sce Atf1 for in vivo ethyl acetate production in E. coli BW25113 $\Delta a c k A \Delta l d h A$ (DE3) under the tested conditions.

The expression of Wan and Kma eat 1 under the control of the $\mathrm{LacI} / \mathrm{T} 7$ promoter resulted in $0.2 \mathrm{C}-\mathrm{mol}_{\text {ethyl }}$ ${ }_{\text {acetate }} / \mathrm{C}$ - $\mathrm{mol}_{\text {glucose }}$ or higher. However, Wan eat 1 required 10 -fold less IPTG to reach the same or higher ethyl acetate yields than Kma eat1 (Fig. 4ab). Moreover, the strains expressing Wan eat 1 under the control of the XylS/Pm promotor produced up to $0.16 \pm 0.01 \mathrm{C}$ - $\mathrm{mol}_{\text {ethyl acetate }} / \mathrm{C}$ mol $_{\text {glucose }}$ (Fig. 4e), whilst Kma eat1 produced almost no ethyl acetate (Fig. 4d). This difference may be explained by the fact that the XylS/Pm promoter is weaker compared to the LacI/T7 promoter [2]. The higher yield obtained with lower gene expression levels indicates that Wan Eat1 was more active than its $K$. marxianus homologue under these cultivation conditions.
The ethyl acetate yields increased with rising inducer concentrations (Fig. 4e, f), reached a plateau (Fig. 4a) and even began to decline at higher inducer concentration (Fig. 4b, c). Determining the optimal inducer concentrations thus resulted in significantly improved ethyl acetate yields. For example, optimised IPTG concentrations used for gene induction in E. coli BW25113 $\Delta a c k A \Delta l d h A$ (DE3) (pET26b:hKma Eat1) led to an increase of the ethyl acetate yield from $0.13 \pm 0.00$ (Fig. 3c) to $0.19 \pm 0.00$ $\mathrm{C}$ - $\mathrm{mol}_{\text {ethyl acetate }} / \mathrm{C}$ - mol $_{\text {glucose }}$ (Fig. 4a). The highest ethyl acetate yield was achieved in E. coli BW25113 $\triangle a c k A \Delta l d h A$ (DE3) (pET26b:hWan Eat1) that was induced with $0.01 \mathrm{mM}$ IPTG. It produced $0.27 \pm 0.01$ $\mathrm{C}$-mol $\mathrm{m}_{\text {ethyl acetate }} / \mathrm{C}$-mol glucose $_{\text {or }} 40.7 \%$ of the theoretical pathway maximum (Fig. 4b).

Selecting the best AAT gene and optimising, its expression level diminished the metabolic bottleneck present in ethyl acetate production, but pyruvate still accumulated (Fig. 4a-f). This indicated that the conversion efficiency of Eat1 was still insufficient to handle the EMP metabolic pathway flux.

\section{Using truncated Eat 1 variants}

Removal of the mitochondrial pre-sequences of $K$. marxianus and $W$. anomalus Eat1 resulted in a higher stability of the enzyme when expressed in E. coli [20]. We tested if this elevated stability also led to more ethyl acetate production. Optimisation of gene expression levels for Kma 

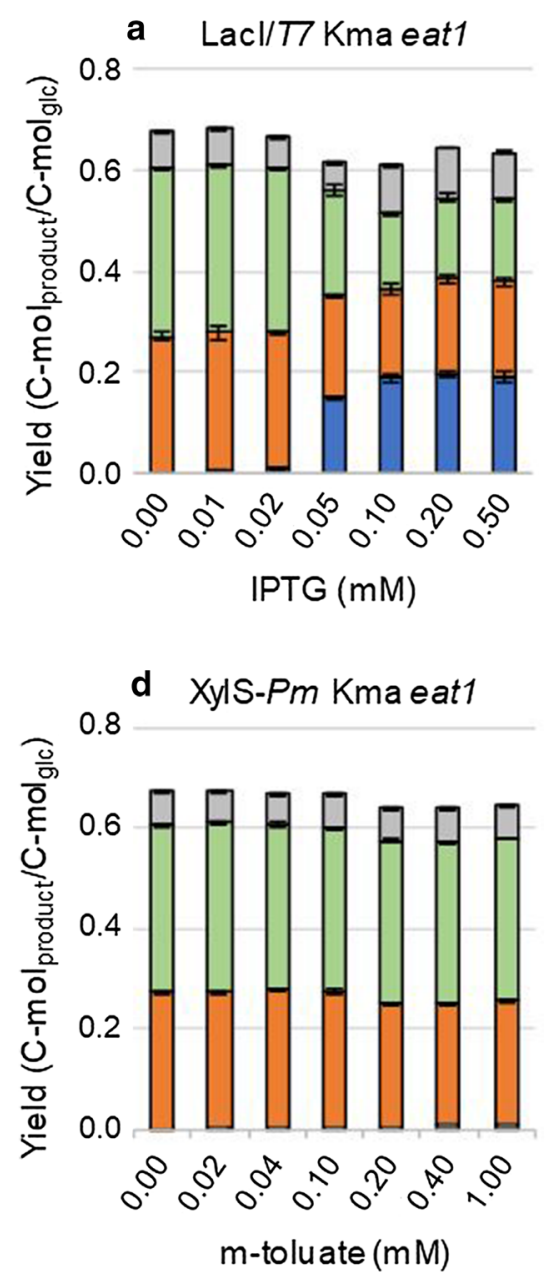

b Lacl/T7 Wan eat1

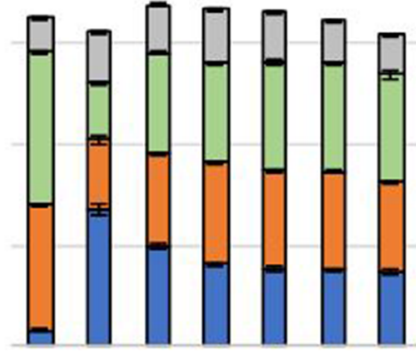

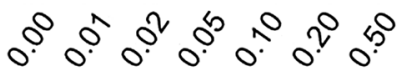

IPTG (mM)

e XylS-Pm Wan eat1

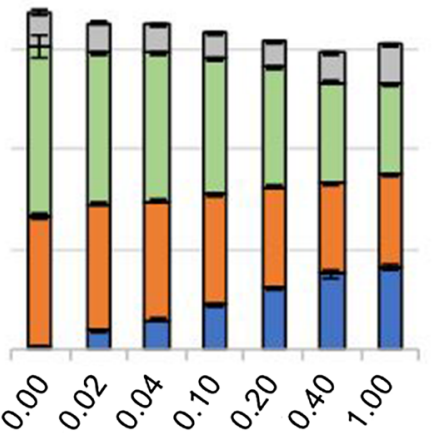

m-toluate (mM) c Lacl/T7 Sce atf1

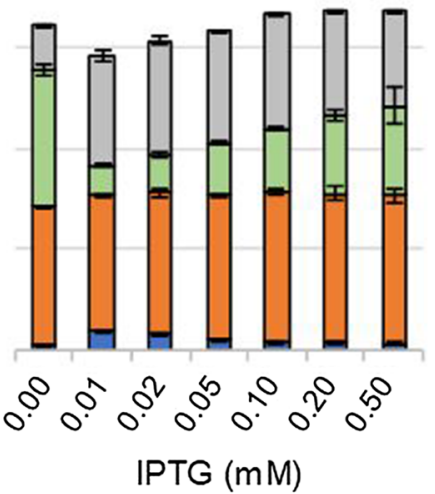

f XylS-Pm Sce atf1

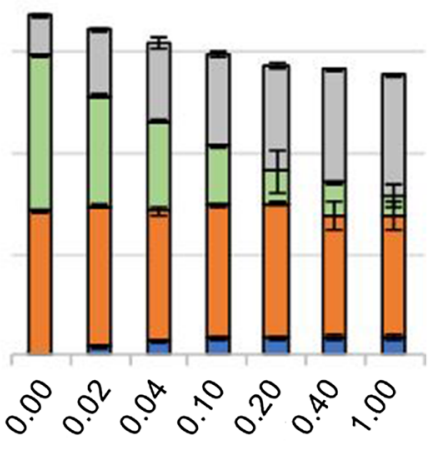

m-toluate $(\mathrm{mM})$

$\square$ Ethyl acetate $\square$ Ethanol $\square$ Pyruvate $\square$ Acetate

Fig. 4 Comparison of three ethyl acetate-producing AAT genes under various gene expression levels, induced by $0.01-0.5$ mM IPTG or 0.02-1 mM m-toluate. a-c Fermentation product yields of strains expressing the Kma eat1, the Wan eat1 and the Sce atf1, respectively, under the control of the Lacl/T7 promoter after $120 \mathrm{~h}$ of cultivation. Gene expression was induced with $0.01-0.5 \mathrm{mM} \mathrm{IPTG}$. $\mathbf{d}-\mathbf{f}$ Fermentation product yields of strains expressing the Kma eat1, the Wan eat1 and the Sce atf1, respectively, under the control of the XylS/Pm promoter after $120 \mathrm{~h}$ of cultivation. Strains were grown in sealed and $\mathrm{N}_{2}$ flushed serum bottles under anaerobic conditions in modified $\mathrm{M} 9$ medium at $30^{\circ} \mathrm{C}$ and $150 \mathrm{rpm}$. Genes were expressed in E. coli BW25113 $\triangle a c k A \triangle I d h A$ (DE3) from a series of pET26b plasmids. Succinate and formate were detected but are not shown. Experiments were performed as biological duplicates; error bars represent the standard deviation

trEat1 F-26 and K-30 resulted in a lower accumulation of pyruvate compared to the unprocessed version (Fig. 5ac), suggesting a higher efficiency of the truncated Eat1 variants. However, this did not result in a higher ethyl acetate yield; only the acetate yield increased.

Nevertheless, the optimum inducer concentration shifted to $0.05 \mathrm{mM}$ IPTG, which was 50\% lower compared to the native Eat1. Ethyl acetate production was also higher at 0.01 and $0.02 \mathrm{mM}$ IPTG, indicating that the in vivo production capacity of ethyl acetate improved. At the same time, the acetate yields increased for induction levels above $0.05 \mathrm{mM}$ IPTG, whilst the pyruvate yields decreased (Fig. 5b, c).

At the lowest IPTG concentration, the strains producing the truncated Wan Eat1 (Wan trEat1 N-13) reached a 3.5-fold higher ethyl acetate yield on glucose than the unprocessed Wan Eat1 (Wan Eat1) (Fig. 5e, f). However, at higher IPTG concentrations these differences were absent. The acetate yield in the strain producing Wan trEat1 N-13 also increased relative to the strain producing Wan Eat1. (Figure 5d, f). The increase in acetate production was not as pronounced as with the Kma trEat1 F-26 and K-30 (Fig. 5a-c). No difference was found 

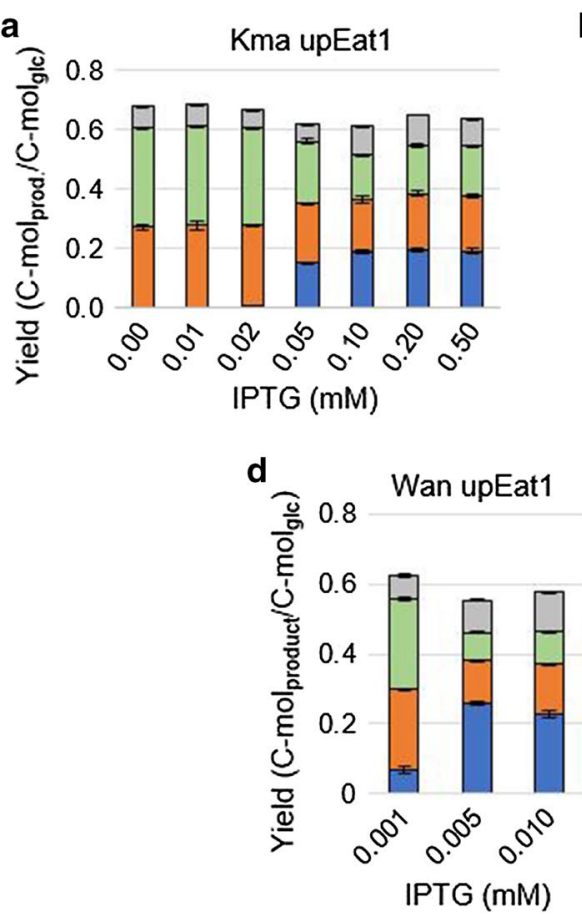

b

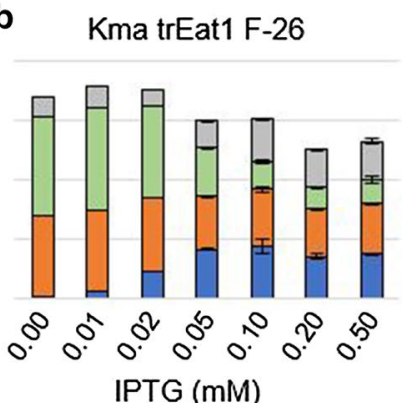

e

Wan trEat1 V-11

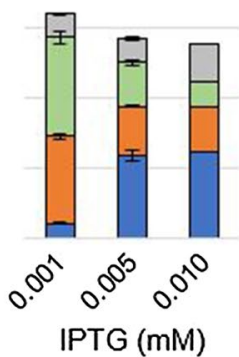

c

C Kma trEat1 K-30

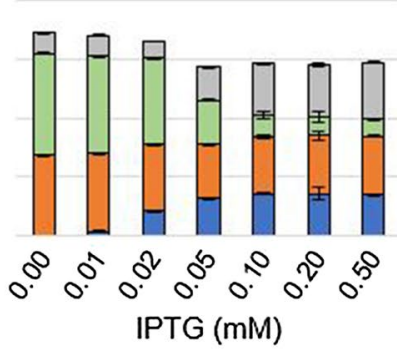

$\square$ Ethyl acetate $\square$ Ethanol $\square$ Pyruvate $\square$ Acetate

Fig. 5 Comparison of truncated eat 1 genes under various gene expression levels induced by 0.01-0.5 mM IPTG or 0.001-0.01 mM IPTG. a-c Fermentation product yields of strains expressing the Kma Eat1, the Kma trEat1 F-26 and the Kma trEat1 K-30, respectively, under the control of the Lacl/T7 promoter after $120 \mathrm{~h}$ of cultivation. Gene expression was induced with 0.01-0.5 mM IPTG. $\mathbf{d}-\mathbf{f}$ Fermentation product yields of strains expressing the Wan Eat1, the Wan trEat1 V-11 and the Wan trEat1 N-13, respectively, under the control of the Lacl/T7 promoter after $120 \mathrm{~h}$ of cultivation. Gene expression was induced with 0.001-0.01 mM IPTG. Strains were grown in sealed and $\mathrm{N}_{2}$ flushed serum bottles under anaerobic conditions in modified $\mathrm{M} 9$ medium at $30^{\circ} \mathrm{C}$ and $150 \mathrm{rpm}$. Genes were expressed in E. coli BW25113 $\triangle a c k A \triangle / d h A$ (DE3) from a series of pET26b plasmids. Succinate and formate were detected but concentrations are not shown. Experiments were performed as biological duplicates; error bars represent the standard deviation. Kma K. marxianus, Wan W. anomalus, Eat1 unprocessed Eat1, trEat1 truncated Eat1

between the Wan trEat1 V-11 and the unprocessed Wan Eat1 (Fig. 5d, e).

As discussed above, a limiting Eat1 efficiency resulted in the accumulation of ethanol. Pyruvate was produced by E. coli BW25113 $\triangle a c k A \Delta l d h A$ (DE3) to counter the redox imbalance caused by ethanol accumulation. The higher stability of the truncated Eat1 versions did indeed result in a decreased pyruvate yield (Fig. 5b, c, e, f) but the ethyl acetate yield did not increase accordingly. Instead, the acetate yield increased, likely due to the esterase and thioesterase side activities of Eat1.

\section{Improving ethyl acetate production with $\mathrm{H}_{\mathbf{2}}$ co-production in controlled bioreactors}

In all serum bottle experiments described above, glucose consumption was incomplete, most likely caused by the accumulation of organic acids, especially formate, and the associated $\mathrm{pH}$ decreased due to a limited buffering capacity of the medium. To avoid limitations caused by medium acidification, additional cultivations were performed in $\mathrm{pH}$-controlled reactors under anaerobic conditions. To limit the accumulation of formate even further, $\mathrm{Na}_{2} \mathrm{SeO}_{3}$ was added to stimulate the conversion of formate into $\mathrm{H}_{2}$ and $\mathrm{CO}_{2}$ by Fhl. A constant flow of nitrogen gas was applied to keep the culture conditions anoxic. This resulted in stripping of ethyl acetate, $\mathrm{H}_{2}$ and $\mathrm{CO}_{2}$ from the broth and the concentrations of these compounds in the exhaust gas were therefore analysed.

We cultivated E. coli BW25113 $\Delta a c k A \Delta l d h A$ (DE3) producing several Eat1 variants. Gene expression was induced with the optimal IPTG concentration of each strain based on the findings of previous experiments (Figs. 4, 5). In contrast to the shake-flask experiments, glucose was fully consumed at the end of the batch fermentations and ethyl acetate production proceeded until glucose was depleted (Fig. 6a, b). Formate was converted into $\mathrm{CO}_{2}$ and $\mathrm{H}_{2}$ by $E$. coli BW25113 $\Delta a c k A \Delta l d h A$ (DE3), but conversion percentages were inconsistent and the conversion was incomplete (Fig. 6 c, d). Strains' conversion was between $6 \%$ and $27 \%$ of the formate into $\mathrm{CO}_{2}$ 


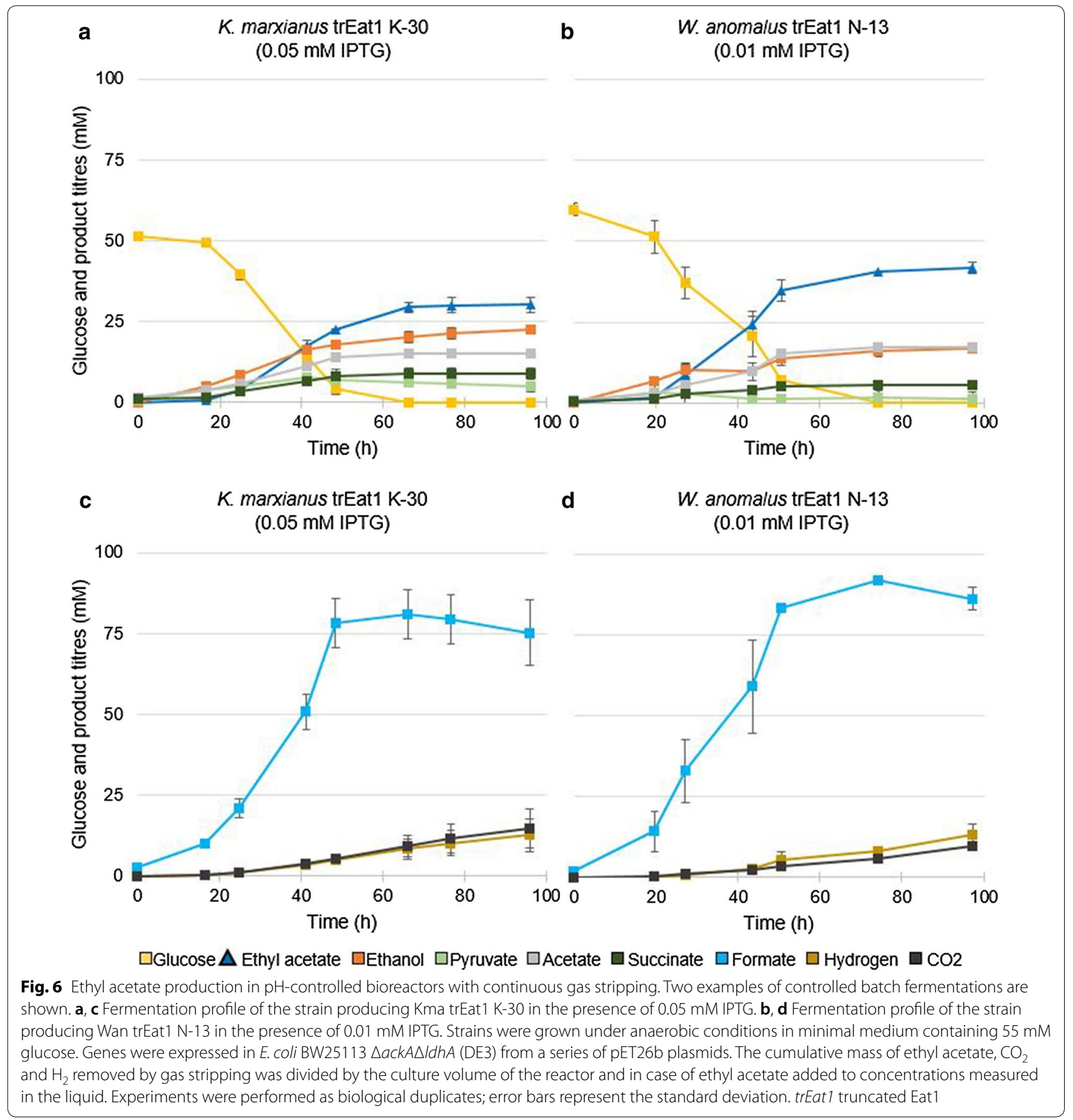

and $\mathrm{H}_{2}$ whilst in most fermentations, the conversion averaged around $10 \%$. There was no correlation between the conversion efficiency, the strain, or reactor vessel. Between 93.0 and $103.7 \%$ of the carbon was recovered in all runs performed when biomass formation and the main fermentation products such as ethyl acetate, ethanol, acetate, pyruvate, formate, succinate and $\mathrm{CO}_{2}$ were included (Fig. 7a, b).
Consistently, all strains cultivated in $\mathrm{pH}$-controlled bioreactors showed improved performance compared to the serum bottle cultivations. Once the unprocessed Kma Eat1 was induced with an optimal $0.1 \mathrm{mM}$ IPTG, a beneficial effect on ethyl acetate yield was apparent. A yield of $0.35 \pm 0.01 \mathrm{C}$ - $\mathrm{mol}_{\text {ethyl acetate }} / \mathrm{C}$ - $\mathrm{mol}_{\text {glucose }}$ corresponded to a 1.8 -fold increase when compared to a serum bottle yield of $0.19 \pm 0.01 \quad \mathrm{C}$ - mol $_{\text {ethyl }}$ 
a

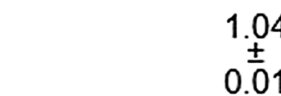

Carbon recovery

1.04
0.01

1.07

0.03

b

Carbon recovery

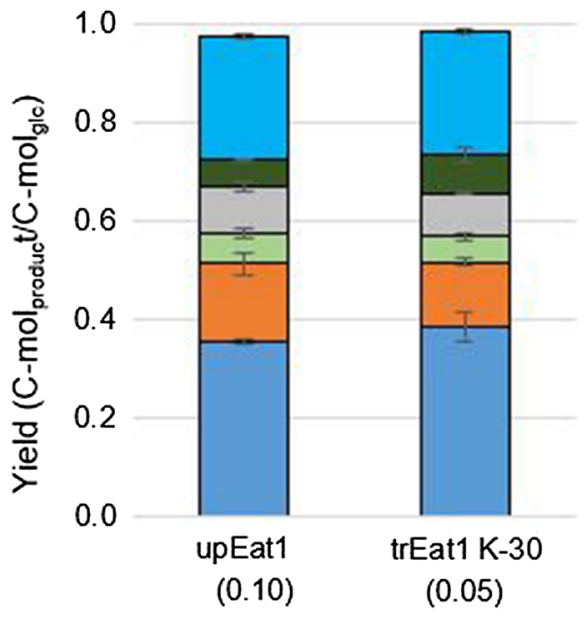

K. marxianus (mM IPTG)

$\begin{array}{ll}0.93 & 0.97 \\ \pm .03 & \pm \pm\end{array}$

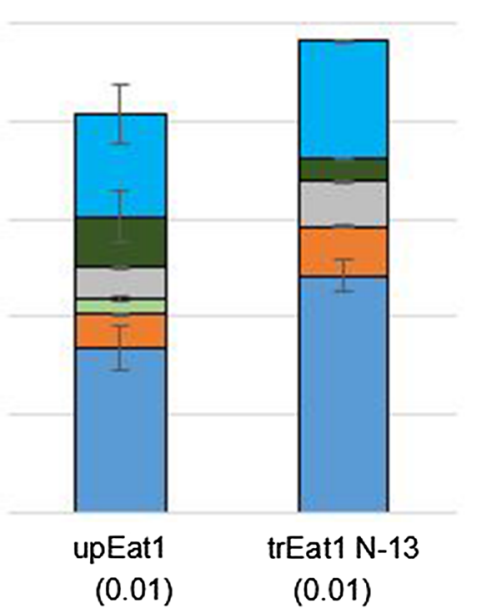

W. anomalus

(mM IPTG)

\section{Ethyl acetate $\square$ Ethanol $\square$ Pyruvate $\square$ Acetate $\square$ Succinate $\square$ Formate + CO2}

C

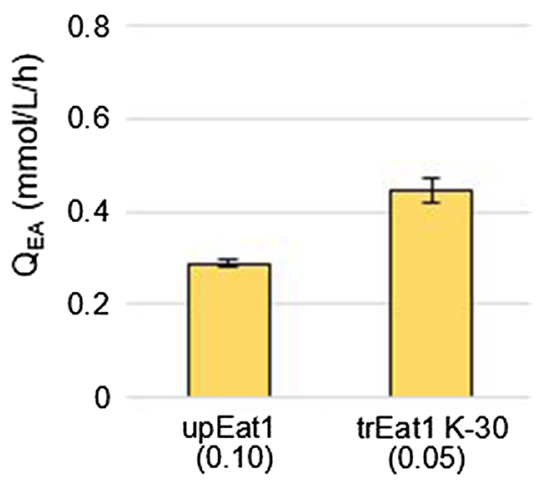

K. marxianus (mM IPTG) d

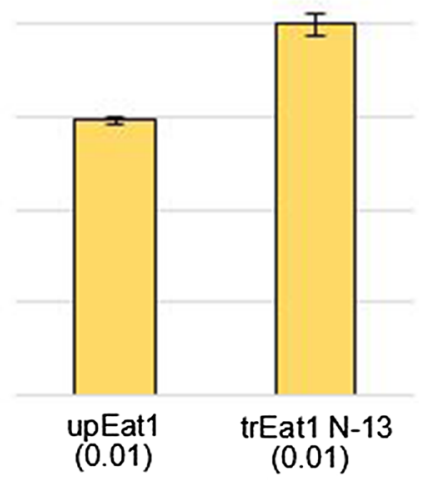

\section{W. anomalus (mM IPTG)}

Fig. 7 Effect of pH-control and continuous ethyl acetate stripping on product yield and volumetric productivity. a Final product yields achieved by cultures producing unprocessed Kma Eat1 and trEat1 K-30 in the presence of 0.05 or 0.1 mM IPTG. The numbers above the bars represent the carbon recovery of the fermentations. $\mathbf{b}$ Final product yields achieved by cultures producing unprocessed Wan Eat1 and trEat1 N-13 in the presence of $0.01 \mathrm{mM}$ IPTG. The numbers above the bars represent the carbon recovery of the fermentations. $\mathbf{c}$, $\mathbf{d}$ The volumetric productivity of ethyl acetate $\left(Q_{E A}\right)$ of the fermentation shown in $\mathbf{a}$ and $\mathbf{b}$, respectively. Strains were grown under anaerobic conditions in minimal medium containing $55 \mathrm{mM}$ glucose. Genes were expressed in E. coli BW25113 $\triangle a c k A \triangle I d h A$ (DE3) from a series of pET26b plasmids. The cumulative mass of ethyl acetate, $\mathrm{CO}_{2}$ and $\mathrm{H}_{2}$ removed by gas stripping was divided by the culture volume of the reactor and in case of ethyl acetate added to concentrations measured in the liquid. Formate and $\mathrm{CO}_{2}$ yields were lumped together to compensate for the variation in $\mathrm{H}_{2}$ formation. Experiments were performed as biological duplicates or triplicates; error bars represent the standard deviation. Eat1 unprocessed Eat1, trEat1 truncated Eat1 
acetate $/ \mathrm{C}-\mathrm{mol}_{\text {glucose }}$, reaching about $50 \%$ of the maximum pathway yield. A similar yield was obtained in strains producing $\mathrm{Kma}$ trEat1 $\mathrm{K}-30$ in the presence of $0.05 \mathrm{mM}$ IPTG (Fig. 7a).

The best producers tested in $\mathrm{pH}$-controlled bioreactors were E. coli BW25113 $\Delta a c k A \Delta l d h A$ (DE3) producing Kma trEat1 K-30 and Wan trEat N-13. They formed $27.6 \pm 3.7 \mathrm{mM}(2.4 \pm 0.3 \mathrm{~g} / \mathrm{L})$ and $42.8 \pm 3.3 \mathrm{mM}$ $(3.8 \pm 0.3 \mathrm{~g} / \mathrm{L})$ ethyl acetate from $55.6 \pm 2.5 \mathrm{mM}$ $(10.0 \pm 0.5 \mathrm{~g} / \mathrm{L})$ glucose, respectively (Fig. 6, Additional file 1). Generally, ethyl acetate yields were between 1.6and 2.8-fold higher in bioreactors compared to serum bottles. The highest yield was obtained by the strain producing Wan trEat1 $\mathrm{N}-13$, reaching $0.48 \pm 0.03 \mathrm{C}^{-m_{\text {ethyl }}}$ acetate $/ \mathrm{C}-\mathrm{mol}_{\text {glucose }}$, or $72.3 \%$ of the maximum pathway yield.

The yields of ethanol and pyruvate decreased with increasing ethyl acetate yields (Fig. 7a, b). Strains producing the unprocessed Kma Eat1 and Kma trEat1 K-30 in the presence of optimal IPTG concentrations accumulated $66 \%$ less pyruvate (Fig. 7a) compared to cultivations in serum bottles (Fig. 5a, c). For the strains producing unprocessed Wan Eat1 and Wan trEat1 N-13 pyruvate accumulation was almost entirely abolished (Figs. 6b and 7b). The ethyl acetate yield for Wan Eat1 was consequently higher compared to the strains producing the Kma Eat1 variants. It should be noted that a statistically significant difference in ethyl acetate yields $(p=0.03)$ was only found for the strain producing Wan trEat1 N-13 (Fig. 7a, b). This strain converted approximately $72 \%$ of glucose to ethyl acetate based on the maximum pathway yield.

Not only did the trEat1 variants require lower induction levels and accumulated less by-products, glucose was also depleted faster. As a result, the volumetric productivity of ethyl acetate $\left(\mathrm{Q}_{E A}\right)$ was higher. The $\mathrm{Q}_{\mathrm{EA}}$ of the strain producing $\mathrm{Kma}$ trEat K-30 (0.05 mM IPTG) was $35 \%$ higher $(p=0.013)$ compared to the strain producing unprocessed Kma Eat1 (0.1 mM IPTG) (Fig. 7c). A similar trend was present in E. coli BW25113 $\Delta a c k A \Delta l d h A$ (DE3) producing unprocessed Wan Eat1 and trEat1 N-13 in the presence of $0.01 \mathrm{mM}$ IPTG. The $\mathrm{Q}_{\mathrm{EA}}$ of the latter strain was $26 \%$ higher $(p$-value $=0.042)$ compared to the strain producing the unprocessed Wan Eat1 (Fig. 7d).

The hydrolysis of ethyl acetate by the side activity of Eat 1 might be restricted by efficiently removing all ethyl acetate by gas stripping. But due to low gas flow rates, ethyl acetate still accumulated in the liquid during the fermentation. At times of maximum productivities, liquid ethyl acetate concentrations ranged from $2.87 \pm 0.1 \mathrm{mM}$ for Kma Eat1 with $0.05 \mathrm{mM}$ IPTG induction to up to $14.7 \pm 0.4 \mathrm{mM}$ for Wan trEat1 N-13 with $0.01 \mathrm{mM}$ IPTG induction (data not shown).

\section{Discussion}

We describe the engineering of $E$. coli for the anaerobic production of ethyl acetate and the different optimisation efforts to further improve the product yield. In all cultivations of the metabolically streamlined $E$. coli BW25113 $\Delta a c k A \Delta l d h A$ (DE3) (pET26b:hKmaEat1) substantial amounts of ethanol and pyruvate were formed, in addition to ethyl acetate. This redox-neutral accumulation of pyruvate and ethanol indicated that the in vivo activity of Eat1 was insufficient to cope with the supply of acetyl-CoA and ethanol.

Screening of $E$. coli strains expressing three different AATs revealed that their capacity to produce ethyl acetate under anaerobic conditions varied significantly. The expression of Sce atf1 evoked acetate production, which may be related to its thioesterase activity [35]. Alternatively, Atf1 may act as an esterase, but this has not been determined. It is unknown whether ethanol inhibits the hydrolytic activity of Sce Atf1 in the same way as was demonstrated for Eat1 [17]. It was observed before that Atf1 exhibits low affinity for the catalysis of ethyl acetate despite external ethanol addition [15]. On the other hand, Sce Atf1 enabled isobutyl acetate production at $80 \%$ of the pathway maximum [38], which indicates that it can be an effective AAT in E. coli. Thus, the inefficient ethyl acetate production by Sce Atf1 may have been caused by differences in substrate specificity or fermentation conditions. However, Atf1 in S. cerevisiae is most active under anaerobic conditions due to higher gene expression [12], suggesting that anoxic conditions should not be a bottleneck in Atf1 activity. Nevertheless, the results of this study disqualified it as catalyst for effective ethyl acetate production under the tested conditions.

Next to plasmid maintenance also inducer compounds are commonly imposing an additional burden to the cells [7, 31]. Whilst the LacI/T7 promoter system is widely applied in molecular engineering studies, it is known to have a strong expression as well as exhibiting some leaky behaviour under non-induced conditions [41]. Moreover, inclusion bodies may form if translation rates are too high and can been a bottleneck in the heterologous expression of AATs [53, 56]. It is possible that lower IPTG concentrations increased the amount of correctly folded protein and led to higher ethyl acetate production. In contrast, the XylS/Pm promoter system is weaker, but remarkably tight and titratable [2]. In the present case, however, the strong LacI/T7 promoter system more efficiently triggered eat 1 activity and ethyl acetate production. Only for Wan Eat1, ethyl acetate formation was observed with the XylS/Pm system. This may result from an overall higher efficiency of the Wan Eat1 variant, compared to Kma Eat1. 
Consistently, Wan Eat1 and its truncated variant were most efficient. Strains producing Wan Eat1 variants formed up to $15 \%$ more ethyl acetate in vivo compared to strains producing Kma Eat1. Optimising the Eat1 efficiency by selecting a better Eat1 variant and improving the expression indeed led to a significant decrease in pyruvate accumulation. Performing similar optimisations on truncated variants, had similar effects, but interestingly also led to lower induction levels for similar or better results. Manual cleavage of the $\mathrm{N}$-termini affected the enzymes' cellular localisation in yeasts and diminished or enhanced catalytic performance in $E$. coli, emphasising the importance of those pre-sequences [20, 25]. Proper cleavage likely improved protein stability, which was reflected by the lower required inducer concentration.

Whilst especially the transfer to $\mathrm{pH}$-controlled reactor systems boosted general performance of the presented ethyl acetate production process, production of other dissimilatory products, like succinate, ethanol and acetate, needs to be further minimised. As fermentations were performed under anaerobic conditions, ethanol and acetate could not be assimilated for additional ethyl acetate formation but remained as by-products of the fermentation. The disruption of ackA did not block acetate synthesis completely. The predominant acetate-forming route under anaerobic conditions is the conversion of acetyl-CoA to acetyl-P and further to acetate [52]. Two genes are involved in this pathway, phosphotransacetylase ( $p t a)$ and acetate kinase ( $a c k A)$, whilst other enzymes with similar catalytic activities, such as propionate kinase are able to perform the same reaction [14]. Disrupting $p t a$ and additional acid kinases might block acetate production completely.

Acetate accumulation by the $a c k A$ knockout strain, and to some extent ethanol accumulation, may also result from the hydrolytic side activities of Eat1. It has been shown that this esterase and thioesterase activity is prevented above a critical ethanol concentration [17]. Below this critical concentration, there was no net ethyl acetate synthesis and ethanol and acetate were produced instead. Under the tested conditions, Atf1 exhibited more esterase and thioesterase activities, barely producing ethyl acetate. The tested eat 1 variants of $W$. anomalus and $K$. marxianus also showed increased acetate levels at higher induction levels. Better understanding of the protein structure and catalytic mechanisms is needed to streamline the desired catalytic activities even further.

A build-up of high formate levels could be detrimental to cell growth and function and might have inhibited the serum bottle fermentations [49]. In batch bioreactors, this problem might be tackled by applying $\mathrm{pH}$ control. Moreover, converting formate to $\mathrm{CO}_{2}$ and $\mathrm{H}_{2}$ via the Fhl complex would allow for co-production of ethyl acetate and $\mathrm{H}_{2}$, the latter also being a valuable biofuel [5]. In our experiments, however, formate was only partially converted (between $6 \%$ and $27 \%$ ), which was also experienced in other studies $[37,54]$. The reason for the high variability is not clear, but it may be due to the complex transcriptional regulation of the 15 genes that are required to form an active Fhl complex [57, 3, 39]. The issue might be prevented in the future by constitutively overexpressing $f h l A$, the transcriptional activator of the Fhl system to improve $\mathrm{H}_{2}$ production [39, 55]. Addition of nickel may also be explored as this compound is required in the functional Fhl system [32].

In situ product removal via gas stripping has already been applied in some yeast production systems [43, 29]. Primarily, it improves downstream processing or can be used to prevent product inhibition during fermentations $[45,19]$. Whilst no critical concentrations of ethyl acetate were reached in the performed fermentations, gas stripping could benefit the fermentations by limiting ethyl acetate hydrolysis. However, temporary accumulation and hydrolysis of ethyl acetate in the medium could not be avoided by the applied stripping rates, particularly for efficient ethyl acetate producers such as Kma trEat1 $\mathrm{K}-30$ or Wan trEat1 N-13. Therefore, performances of the respective strains may still improve when higher stripping rates are applied.

Whilst the reduction of degradation of the product by gas stripping improves the performance in the current research, it primarily aims at preventing product toxicity [19]. Currently the reached titres of ethyl acetate are well below toxic levels for $E$. coli [51] but higher inoculation densities and the switch to fed-batch systems should benefit the final product titres. Whether the volumetric productivities can also compete with those reached by aerobic systems, is another factor that needs to be evaluated in the future.

The yield of $72 \%$ of the maximum pathway did already exceed the best ethyl acetate yield reported for $K$. marxianus converting whey sugars (predominantly lactose) to ethyl acetate under aerobic conditions, reaching $56 \%$ of the theoretical maximum pathway yield [45].

\section{Conclusion}

We demonstrated that E. coli can be engineered to efficiently convert glucose to ethyl acetate as the primary fermentation product, which may serve as a point of reference for future development of biobased ethyl acetateproduction processes in which Eat1 serves as the AAT catalyst. The combined effects of several rounds of metabolic, protein and process engineering resulted in an up to 14.3-fold increase in ethyl acetate yield. The highest ethyl acetate yield was achieved with $E$. coli BW25113 $\triangle a c k A \Delta l d h A$ (DE3) producing Wan trEat1 N-13 in 
the presence of $0.01 \mathrm{mM}$ IPTG. This strain formed $0.49 \pm 0.03 \mathrm{C}$ - $\mathrm{mol}_{\text {ethyl acetate }} / \mathrm{C}-\mathrm{mol}_{\text {glucose }}$ which corresponds to $\sim 72 \%$ of the theoretical pathway maximum.

\section{Materials and methods}

\section{Strain and plasmid construction}

The strains and plasmids used in this study are listed in Tables 1 and 2, respectively. The pET26b-XylS/Pm plasmids were obtained by replacing the lacI/T7 promoter of pET26b with the XylS/Pm promoter [2] using $2 \mathrm{X} \mathrm{HiFi}$ assembly master mix (NEB) according to the supplier protocol. All $K$. marxianus and W. anomalus eat 1 genes were cloned with a Strep-tag or 6-His-tag, respectively, to facilitate protein purification. PCR amplifications were performed with Q5 polymerase (NEB) according to supplier instructions.

\section{Cultivation}

Routinely, E. coli strains were grown on LB medium supplemented with kanamycin $(50 \mu \mathrm{g} / \mathrm{mL})$ or spectinomycin $(50 \mu \mathrm{g} / \mathrm{mL})$. Sterile $250-\mathrm{mL}$ serum bottles were filled with $50 \mathrm{~mL}$ modified $\mathrm{M} 9$ medium, consisting of $\mathrm{M} 9$ salts (Difco, 1X), glucose (55 mM), $\mathrm{MgSO}_{4}(2 \mathrm{mM}), \mathrm{CaCl}_{2}{ }^{*} 2$ $\mathrm{H}_{2} \mathrm{O}(0.1 \mathrm{mM})$, MOPS $(100 \mathrm{mM})$ and $1 \mathrm{~mL} 1000 \mathrm{X}$ trace elements and vitamins each according to Verduyn et al. [46], and used for anaerobic cultivation experiments.
The serum bottles were made anaerobic by flushing with nitrogen. For precultures single colonies were transferred to $10 \mathrm{~mL} \mathrm{LB}$ medium in a $50-\mathrm{mL}$ tube and grown overnight at $30{ }^{\circ} \mathrm{C}$ and $250 \mathrm{rpm}$. A second overnight cultivation under same conditions was performed after 1-2 $\mathrm{mL}$ of the LB culture was transferred to $50 \mathrm{~mL}$ modified M9 medium in a $250-\mathrm{mL}$ Erlenmeyer flask. The anaerobic serum bottles were inoculated to an initial OD of 0.2 and incubated at $30{ }^{\circ} \mathrm{C}$ and $150 \mathrm{rpm}$. The inducing reagents isopropyl $\beta$-D-1-thiogalactopyranoside (IPTG) (0.01$0.5 \mathrm{mM})$ or $\mathrm{m}$-toluate $(0.021 \mathrm{mM})$ were added to induce gene expression when appropriate. Experiments were performed as biological duplicates. Ethyl acetate production in serum bottles was measured only in the liquid phase.

\section{Batch fermentations}

Anaerobic fermentations were performed in 1.5-L bioreactors (Applikon) in $0.5 \mathrm{~L}$ defined medium. The fermentation medium contained glucose $(55 \mathrm{mM}),(\mathrm{NH} 4)_{2} \mathrm{SO}_{4}$ (37.8 mM), $\mathrm{KH}_{2} \mathrm{PO}_{4}(22 \mathrm{mM}), \mathrm{NaCl}(171 \mathrm{mM})$, kanamycin $(100 \mu \mathrm{g} / \mathrm{mL})$ and $\mathrm{Na}_{2} \mathrm{SeO}_{3}(0.3 \mathrm{mg} / \mathrm{L})$ to promote hydrogen formation, unless mentioned otherwise. The medium was supplemented with vitamins and trace elements [46]. The fermentation broth was stirred at $400 \mathrm{rpm}$ with a Rushton turbine controlled by an ADI 1012 Motor Controller

Table 1 Strains used in this study

\begin{tabular}{|c|c|c|}
\hline Strain & Characteristics & Source \\
\hline Escherichia coli BW25113 (DE3) & Wild type with integrated DE3 lysogen & {$[48]$} \\
\hline Escherichia coli BW25113 $\triangle a c k A \triangle / d h A$ & Disruption of lactate and acetate production (via ackA) & {$[20]$} \\
\hline Escherichia coliT7 Express & $\begin{array}{l}\text { fhuA2 [lon] ompT gal }(\lambda \text { DE3) }[\mathrm{dcm}] \triangle \text { hsdS } \\
\lambda \text { DE3 }=\lambda \text { sBamHIo } \triangle \text { ECoRI-B int::(Lacl::PlacUV5::T7 gene1) i21 } \Delta \text { nin5 }\end{array}$ & NEB \\
\hline Escherichia coli NEB ${ }^{\circledR} 5$-alpha & $\begin{array}{l}\text { fhuA2 } \triangle \text { (argF-lacZ)U169 phoA glnV44 } \$ 80 \triangle(\text { lacZ)M15 gyrA96 recA1 relA1 endA1 } \\
\text { thi-1 hsdR17 }\end{array}$ & NEB \\
\hline
\end{tabular}

Table 2 Plasmids used in this study

\begin{tabular}{|c|c|c|c|}
\hline Plasmid & Promoter & Gene/Protein & Source \\
\hline pET26b & $\mathrm{Lacl} / \mathrm{T7}$ & / & This study \\
\hline pET26b:hWanEat1 & $\mathrm{Lacl} / \mathrm{T7}$ & Codon harmonised eat1 from Wickerhamomyces anomalus DSM 6766 & {$[17]$} \\
\hline pET26b:hKmaEat1 & $\mathrm{Lacl} / \mathrm{T7}$ & Codon harmonised eat1 from Kluyveromyces marxianus DSM 5422 & {$[20]$} \\
\hline pET26b:opSceAtf1 & $\mathrm{Lacl} / \mathrm{T7}$ & Codon optimised atf1 from Saccharomyces cerevisiae [38] & This study \\
\hline pET26b: XylS/Pm -hWanEat1 & $\mathrm{XyIS} / \mathrm{Pm}$ & Codon harmonised eat1 from Wickerhamomyces anomalus DSM 6766 & This study \\
\hline pET26b: XylS/Pm hKmaEat1 & XylS/Pm & Codon harmonised eat1 from Kluyveromyces marxianus DSM 5422 & This study \\
\hline pET26b: XylS/Pm opSceAtf1 & $\mathrm{XylS} / \mathrm{Pm}$ & Codon optimised atf1 from Saccharomyces cerevisiae & This study \\
\hline pET26b:hKma trEat1 F-26 & $\mathrm{Lacl} / \mathrm{T7}$ & Kma Eat1 truncated at F-26 & {$[20]$} \\
\hline pET26b:hKma-trEat1-K30 & $\mathrm{Lacl} / \mathrm{T7}$ & Kma Eat1 truncated at K-30 & {$[20]$} \\
\hline pET26b:hWan-trEat1-V11 & $\mathrm{Lacl} / \mathrm{T7}$ & Wan Eat1 truncated at V-11 & {$[20]$} \\
\hline pET26b:hWan-trEat1-N13 & $\mathrm{LaCl} / \mathrm{T7}$ & Wan Eat1 truncated at N-13 & {$[20]$} \\
\hline
\end{tabular}


(Applikon). $\mathrm{pH}$ was kept constant at 7.0 by automatic addition of $3 \mathrm{M} \mathrm{KOH}$ or $0.5 \mathrm{M} \mathrm{H}_{2} \mathrm{SO}_{4}$. The temperature was controlled at $30^{\circ} \mathrm{C}$ by a Thermo Circulator ADI 1018 (Applikon). Anaerobic conditions were maintained using oxygen-impermeable Marprene tubing (Watson-Marlow) and constant sparging with $3 \mathrm{~L} / \mathrm{h} \mathrm{N} \mathrm{N}_{2}$. Inocula were prepared by transferring $0.5 \mathrm{~mL}$ fresh overnight $\mathrm{LB}$ pre-culture to $50 \mathrm{~mL}$ modified M9 medium in a $250-\mathrm{mL}$ Erlenmeyer flask. The culture was grown overnight aerobically at $30^{\circ} \mathrm{C}$ and $250 \mathrm{rpm}$. The reactors were inoculated to an initial $\mathrm{OD}_{600}$ of 0.4 . Metabolites in the liquid phase were measured by high-performance liquid chromatography (HPLC) and gas chromatography coupled to a flame ionisation detector (GC-FID). Online measurements of volatile compounds and gases removed from the vessel by gas stripping were performed with a $\delta B$ Process Mass Spectrometer (MS, Thermo Scientific ${ }^{\mathrm{TM}}$ ).

\section{Calculations}

The gaseous concentration of ethyl acetate, $\mathrm{CO}_{2}$ and $\mathrm{H}_{2}$ $\left(\mathrm{C}_{\mathrm{C} \text {, gas }}, \mathrm{mol} / \mathrm{L}\right)$ in the outflow was calculated based on the ideal gas law according to Eq. 1 follows:

$$
C_{C, \text { gas }}=\frac{\frac{X_{C, g a s}}{P_{a t m}}}{R * T}
$$

With $\mathrm{C}$ representing the corresponding compound (ethyl acetate, $\mathrm{CO}_{2}$ and $\mathrm{H}_{2}$ ), $\mathrm{X}_{\mathrm{C} \text {, gas }}$ the volumetric fraction of compound $\mathrm{C}$ in the gas (-), $\mathrm{P}_{\mathrm{atm}}$ the atmospheric pressure $(\mathrm{Pa}), \mathrm{R}$ the ideal gas constant $\left(\mathrm{m}^{3} \mathrm{~Pa} / \mathrm{mol} / \mathrm{K}\right)$ and $\mathrm{T}$ the temperature $(\mathrm{K})$. The cumulative mass of compound $\mathrm{C}\left(\mathrm{m}_{\mathrm{C}, \mathrm{gas}}\right.$, mol) stripped up to each time point $\left(\mathrm{t}_{\mathrm{n}}\right.$, h) was calculated using Eq. 2 .

$$
\begin{aligned}
m_{C, \text { gas }}\left(t_{n}\right)= & \frac{C_{C, \text { gas }}\left(t_{n-1}\right)+C_{C, \text { gas }}\left(t_{n}\right)}{2} \\
& * \frac{F_{\text {gas }, \text { out }}\left(t_{n-1}\right)+F_{\text {gas }, \text { out }}\left(t_{n}\right)}{2} \\
& * \Delta t+m_{C, \text { gas }}\left(t_{n-1}\right)
\end{aligned}
$$

where the average gaseous concentration of the product between time points $t_{\mathrm{n}-1}$ and $t_{\mathrm{n}}$ is calculated from Eq. 1 $(\mathrm{mol} / \mathrm{L}), F_{\text {gas,out }}$ is the total volumetric gas flow rate leaving the reactor $(\mathrm{L} / \mathrm{h}), \Delta \mathrm{t}$ is the time between two time points (h) and $m_{\mathrm{C}, \text { gas }}\left(\mathrm{t}_{\mathrm{n}-1}\right)$ is the amount of compound $\mathrm{C}$ stripped up to the previous time point (mol). $F_{\text {gas,out }}$ was calculated assuming $N_{2}$ as an inert gas and knowing the total volumetric gas flow into the reactor $\left(F_{\text {gas,in }}\right)$ and the volumetric fractions of $N_{2}$ in the corresponding in- and outflows $\left(X_{\mathrm{N} 2, \text { in }}, X_{\mathrm{N} 2 \text {,out }}\right)$ at time point $t$ using Eq. 3.

$$
F_{\text {gas }, \text { out }}=\frac{X_{N 2, \text { in }}}{X_{N 2, \text { out }}} * F_{\text {gas }, \text { in }}
$$

The cumulative mass of stripped ethyl acetate after Eq. 3 was divided by the culture volume in the bioreactor and added to the current ethyl acetate concentration in the liquid. The resulting value is an apparent ester concentration at time $t_{\mathrm{n}}$ which would be found in the culture medium if no stripping was applied.

\section{Carbon balance calculation}

Carbon balances were calculated according to Eq. 4.

$$
C_{\text {balance }}=\frac{\mathrm{C}-\text { mol products formed }}{\mathrm{C}-\text { mol glucose consumed }}
$$

The compounds included in the calculation were glucose, ethyl acetate, ethanol, acetate, succinate, pyruvate, formate and $\mathrm{CO}_{2}$. Biomass formation was included in the calculation assuming a biomass composition of $\mathrm{CH}_{2} \mathrm{O}_{0.5} \mathrm{~N}_{0.2}$ and an experimentally determined conversion factor of 0.3232 from $\mathrm{OD}_{600}$ to $\mathrm{g} / \mathrm{L}$ dry weight (data not shown).

\section{Analytical}

Glucose and organic acids were analysed by HPLC on an Agilent 1290 LC II system, equipped with an Agilent 1290 Infinity Binary Pump, Agilent 1290 Infinity Autosampler, Agilent 1290 Infinity diode array detector operated at $210 \mathrm{~nm}$, and an Agilent 1260 Infinity RI detector operated at $45^{\circ} \mathrm{C}$. Either an Aminex HPX-87H (Bio-Rad) or a Rezex ROA-Organic Acid H + (Phenomenex) column was used with a mobile phase of $0.008 \mathrm{mM} \mathrm{H}_{2} \mathrm{SO}_{4}$. The HPLC was operated at $0.8 \mathrm{~mL} / \mathrm{min}$ and $60{ }^{\circ} \mathrm{C}$. Propionic acid $(50 \mathrm{mM})$ was used as an internal standard.

Ethyl acetate and ethanol in liquid samples were measured by an Agilent 7890B gas chromatograph equipped with a flame ionisation detector (GC-FID) and an Agilent 7693 autosampler. Samples were analysed by injecting $0.5 \mu \mathrm{L}$ of liquid sample onto a Nukol ${ }^{\mathrm{TM}}$ column (30 $\mathrm{m} \times 0.53 \mathrm{~mm}, 1.0 \mu \mathrm{m}$ coating, Supelco). The column temperature was maintained at $50{ }^{\circ} \mathrm{C}$ for 2 min and increased to $200{ }^{\circ} \mathrm{C}$ at a rate of $50{ }^{\circ} \mathrm{C} / \mathrm{min}$. The split ratio was 10.1 -Butanol $(2 \mathrm{mM})$ was used as an internal standard.

\section{Supplementary information}

Supplementary information accompanies this paper at https://doi. org/10.1186/s13068-020-01703-1.

Additional file 1: Table S1. Overview of pH-controlled batch fermentations in 1.5L Applikon bioreactors with continuous gas stripping. Measured and calculated concentrations of main fermentation products, carbon balance and C-mol yields at end of fermentations are represented as average (AV) with standard deviations (SD) for each duplicate. E. coli BW25113 $\triangle a c k A \triangle / d h A$ (DE3) producing Eat1 variants from pET26b plasmids were grown under anoxic conditions in minimal medium containing 55 mM glucose. Expression of Eat1 was induced by IPTG. 


\section{Abbreviations}

AA: Amino acid; AAT: Alcohol acetyl transferase; Adh: Alcohol/aldehyde dehydrogenase; AckA: Acetate kinase; Acs: Acetyl-CoA synthetase; Ald: Acetaldehyde dehydrogenase; Atf1: Alcohol acetyltransferase $1 ; C_{C \text {, gas: }}$ : Gaseous concentration of compound C (mol/L); EA: Ethyl acetate; Eat1: Ethanol acetyltransferase 1; EMP: Embden-Meyerhof-Parnas; $F_{\text {gas,in }}$ :Total volumetric gas flow into the reactor $(L / h) ; F_{\text {gas out }}:$ Total volumetric gas flow rate leaving the reactor $(L / h)$; Fhl: Formate hydrogen lyase; IPTG: Isopropyl B-D-1-thiogalactopyranoside; Kma: Kluyveromyces marxianus; Ldh: Lactate dehydrogenase; $m_{C, \text { gas }}$ (cumulative) Molar mass of compound $C$ in gas phase $(\mathrm{mol}) ; P_{\text {atm: }}$ : Atmospheric pressure (Pa); Pdc: Pyruvate decarboxylase; Pfl: Pyruvate formate lyase; Pr: Fermentation products; Pta: Phosphotransacetylase; $\mathrm{Q}_{\mathrm{EA}}$ : Volumetric productivity of ethyl acetate $(\mathrm{mmol} / \mathrm{L} / \mathrm{h}) ; \mathrm{R}$ : Ideal gas constant (8.314 J/mol/K); Sce: Saccharomyces cerevisiae; T: Temperature $(\mathrm{K}) ; t_{\mathrm{n}}$ : Time point (h); trEat1: Truncated Eat1; Wan: Wickerhamomyces anomalus; $X_{C, \text { gas }}$ :Volumetric fraction of compound $C$ in the gas $(L / L)$.

\section{Acknowledgements}

Not applicable.

\section{Authors' contributions}

AB, AK, AM, SK, RW, JvO and RAW designed the work. AB and AK conducted, analysed and interpreted the experiments. $A K$ and $A B$ drafted and wrote the manuscript. All authors read and approved the final manuscript.

\section{Funding}

We would like to acknowledge the BE-Basic foundation, TKI Energy and Nouryon for funding the research.

\section{Availability of data and materials}

All data generated or analysed during this study are included in this published article and its additional information files.

\section{Ethics approval and consent to participate}

Not applicable.

\section{Consent for publication}

Not applicable.

\section{Competing interests}

The authors declare that they have no competing interests.

\section{Author details}

${ }^{1}$ Bioprocess Engineering, Wageningen University and Research, Droevendaalsesteeg 1, 6708 PB Wageningen, The Netherlands. ${ }^{2}$ Laboratory of Microbiology, Wageningen University and Research, Stippeneng 4, 6708 WE Wageningen, The Netherlands. ${ }^{3}$ Biobased Products, Wageningen University and Research, Bornse Weilanden 9, 6708 WG Wageningen, The Netherlands. ${ }^{4}$ Faculty of Biosciences and Aquaculture, Nord University, 8049 Bodø, Norway.

Received: 23 January 2020 Accepted: 25 March 2020 Published online: 07 April 2020

\section{References}

1. Armstrong DW, Martin SM, Yamazaki H. Production of ethyl acetate from dilute ethanol solutions by Candida utilis. Biotechnol Bioeng. 1984;26(9):1038-41. https://doi.org/10.1002/bit.260260905.

2. Balzer S, et al. A comparative analysis of the properties of regulated promoter systems commonly used for recombinant gene expression in Escherichia coli. Microb Cell Fact. 2013;12(1):1-14. https://doi. org/10.1186/1475-2859-12-26.

3. Birkmann A, et al.'Factors affecting transcriptional regulation of the formate-hydrogen-lyase pathway of Escherichia coli. Archiv Microbiol. 1987;148(1):44-51. https://doi.org/10.1007/bf00429646.

4. Blanch HW. Bioprocessing for biofuels. Curr Opin Biotechnol. 2012. https ://doi.org/10.1016/j.copbio.2011.10.002.

5. Brentner LB, Peccia J, Zimmerman JB. Challenges in developing biohydrogen as a sustainable energy source: implications for a research agenda.
Environ Sci Technol. 2010;44(7):2243-54. https://doi.org/10.1021/es903 0613.

6. Davies R, et al. Ester formation by yeasts 1. Ethyl acetate formation by Hansenula species. Biochem J. 1951;49(1):58-61.

7. Diaz Ricci JC, Hernández ME. Plasmid effects on Escherichia coli metabolism. Crit Rev Biotechnol. 2000;20(2):79-108. https://doi. org/10.1080/07388550008984167.

8. van Dijken JP, Weusthuis RA, Pronk JT. Kinetics of growth and sugar consumption in yeasts. Antonie van Leeuwenhoek. Kluwer Acad Publishers. 1993;63(3-4):343-52. https://doi.org/10.1007/BF00871229.

9. Dzialo MC, et al. Physiology, ecology and industrial applications of aroma formation in yeast. FEMS Microbiol Rev. 2017;41((Supp_1)):S95-128. https ://doi.org/10.1093/femsre/fux031.

10. Fischer E, Speier A. Darstellung der Ester. Chem Ber. 1895;28:3252-8.

11. Fredlund $E$, et al. Oxygen- and glucose-dependent regulation of central carbon metabolism in Pichia anomala. Appl Environ Microbiol. 2004;70(10):5905-11. https://doi.org/10.1128/Aem.70.10.5905-5911.2004.

12. Fujiwara $D$, et al. Molecular mechanism of the multiple regulation of the Saccharomyces cerevisiae ATF1 gene encoding alcohol acetyltransferase. Yeast. 1999. https://doi.org/10.1002/(SICI)1097-0061(19990 915) 15:12\%3c1183:AID-YEA444\%3e3.0.CO;2-J.

13. Garcia-Ochoa F, Gomez E. Bioreactor scale-up and oxygen transfer rate in microbial processes: an overview. Biotechnol Adv Elsevier. 2009;27(2):153-76. https://doi.org/10.1016/J.BIOTECHADV.2008.10.006.

14. Heßlinger C, Fairhurst SAA, Sawers G. Novel keto acid formate-lyase and propionate kinase enzymes are components of an anaerobic pathway in Escherichia coli that degrades L-threonine to propionate. Mol Microbiol. 1998;27(2):477-92.

15. Horton CE, Bennett GN. Ester production in E. coli and C. acetobutylicum. Enzyme Microbial Technol. 2006;38(7):937-43. https://doi.org/10.1016/j. enzmictec.2005.08.025.

16. Jyoti $\mathrm{G}$, et al. Homogeneous and heterogeneous catalyzed esterification of acrylic acid with ethanol: reaction kinetics and modeling. Int J Chem Kinetics. 2018;50(5):370-80. https://doi.org/10.1002/kin.21167.

17. Kruis AJ, et al. Ethyl acetate production by the elusive alcohol acetyltransferase from yeast. Metab Eng. 2017;41:92-101. https://doi.org/10.1016/j. ymben.2017.03.004

18. Kruis AJ, et al. The alcohol acetyltransferase Eat1 is located in yeast mitochondria. Appl Environ Microbiol Am Soc Microbiol. 2018;84(19):e01640-18.

19. Kruis AJ, et al. Microbial production of short and medium chain esters: enzymes, pathways, and applications. Biotechnol Adv. 2019. https://doi. org/10.1016/j.biotechadv.2019.06.006.

20. Kruis, A. J. et al. (in submission) From Eat to trEat: Engineering the mitochondrial Eat1 enzyme for enhanced ethyl acetate production in Escherichia coli. https://doi.org/10.21203/rs.2.19484/v1.

21. Layton DS, Trinh CT. Expanding the modular ester fermentative pathways for combinatorial biosynthesis of esters from volatile organic acids. Biotechnol Bioeng. 2016;113(8):1764-76. https://doi.org/10.1002/bit.25947.

22. Lee J-W, Trinh CT. Microbial biosynthesis of lactate esters. Biotechnol Biofuels. 2019. https://doi.org/10.1186/s13068-019-1563-z.

23. Lee, J. and Trinh, C. T. (2018) 'De novo microbial biosynthesis of a lactate ester platform, bioRxiv, p. 498576. https://doi.org/10.1101/498576.

24. Liu Y, Lotero E, Goodwin JG. Effect of water on sulfuric acid catalyzed esterification. J Mol Catalysis Chem. 2006;245(1-2):132-40. https://doi. org/10.1016/J.MOLCATA.2005.09.049.

25. Löbs A-K, et al. CRISPR-Cas9-enabled genetic disruptions for understanding ethanol and ethyl acetate biosynthesis in Kluyveromyces marxianus. Biotechnol Biofuels BioMed Central. 2017;10(1):164. https://doi. org/10.1186/s13068-017-0854-5.

26. Löser $C$, et al. Formation of ethyl acetate by Kluyveromyces marxianus on whey during aerobic batch and chemostat cultivation at iron limitation. Appl Microbiol Biotechnol. 2012;96(3):685-96. https://doi.org/10.1007/ s00253-012-4205-y.

27. Löser $C$, et al. Formation of ethyl acetate from whey by Kluyveromyces marxianus on a pilot scale. J Biotechnol. 2013;163(1):17-23. https://doi. org/10.1016/j.jbiotec.2012.10.009.

28. Löser C, Urit T, Gruner E, et al. Efficient growth of Kluyveromyces marxianus biomass used as a biocatalyst in the sustainable production of ethyl acetate. Energy Sustain Soc. 2015;5(1):2. https://doi.org/10.1186/s1370 5-014-0028-2. 
29. Löser C, Urit T, Keil P, et al. Studies on the mechanism of synthesis of ethyl acetate in Kluyveromyces marxianus DSM 5422. Appl Microbiol Biotechnol. 2015;99(3):1131-44. https://doi.org/10.1007/s00253-014-6098-4.

30. Löser C, Urit T, Bley T. Perspectives for the biotechnological production of ethyl acetate by yeasts. Appl Microbiol Biotechnol. 2014;98(12):5397-415. https://doi.org/10.1007/s00253-014-5765-9.

31. Malakar P, Venkatesh KVV. Effect of substrate and IPTG concentrations on the burden to growth of Escherichia coli on glycerol due to the expression of Lac proteins. Appl Microbiol Biotechnol. 2012;93(6):2543-9. https://doi. org/10.1007/s00253-011-3642-3.

32. McDowall JS, et al. Bacterial formate hydrogenlyase complex. Proc Natl Acad Sci U S A. 2014;111(38):E3948-56. https://doi.org/10.1073/ pnas. 1407927111.

33. Minetoki T, et al. The purification, properties and internal peptide sequences of alcohol acetyltransferase isolated from Saccharomyces cerevisiae Kyokai No. 7. Biosci Biotechnol Biochem. 1993;57(12):2094-8.

34. Mossmann D, Meisinger C, Vögtle FN. Processing of mitochondrial presequences. Biochimica et Biophysica Acta Gene Regul Mech. 2012;1819(910):1098-106. https://doi.org/10.1016/j.bbagrm.2011.11.007.

35. Nancolas B, et al. Saccharomyces cerevisiae Atf1 p is an alcohol acetyltransferase and a thioesterase in vitro. Yeast. 2017;34(6):239-51. https://doi. org/10.1002/yea.3229.

36. Peel JL. Ester formation by yeasts 2 . Formation of ethyl acetate by washed suspensions of Hansenula anomala. Biochem J. 1951:49(1):62-7.

37. Penfold DW, Forster CF, Macaskie LE. Increased hydrogen production by Escherichia coli strain HD701 in comparison with the wild-type parent strain MC4100. Enzyme Microbial Technolo. 2003;33(2-3):185-9. https:// doi.org/10.1016/S0141-0229(03)00115-7.

38. Rodriguez GM, Tashiro Y, Atsumi S. Expanding ester biosynthesis in Escherichia coli. Nat Chem Biol. 2014;10(4):259-65. https://doi.org/10.1038/ nchembio.1476.

39. Rossmann R, Sawers G, Böck A. Mechanism of regulation of the formate-hydrogenlyase pathway by oxygen, nitrate, and $\mathrm{pH}$ : definition of the formate regulon. Mol Microbiol. 1991;5(11):2807-14. https://doi. org/10.1111/j.1365-2958.1991.tb01989.x.

40. Stephen AJ, et al. Advances and bottlenecks in microbial hydrogen production. Microbial Biotechnol. 2017;10(5):1120-7. https://doi. org/10.1111/1751-7915.12790.

41. Tabor S, Richardson CC. A bacteriophage T7 RNA polymerase/promoter system for controlled exclusive expression of specific genes. Proc Natl Acad Sci U S A. 1985;82(4):1074-8. https://doi.org/10.1073/ pnas.82.4.1074

42. The Market Publishers (2014) Global ETAC production to exceed 3.5 M/n tonnes in 2015, according to new report by Merchant Research and Consulting, prweb.

43. Urit T, et al. Formation of ethyl acetate by Kluyveromyces marxianus on whey: studies of the ester stripping. Bioprocess Biosyst Eng. 2011;34(5):547-59. https://doi.org/10.1007/s00449-010-0504-9.

44. Urit T, Manthey R, et al. Formation of ethyl acetate by Kluyveromyces marxianus on whey: influence of aeration and inhibition of yeast growth by ethyl acetate. Eng Life Sci. 2013;13(3):247-60. https://doi.org/10.1002/ elsc.201200077.
45. Urit T, Li M, et al. Growth of Kluyveromyces marxianus and formation of ethyl acetate depending on temperature. Appl Microbiol Biotechnol. 2013;97(24):10359-71. https://doi.org/10.1007/s00253-013-5278-y.

46. Verduyn C, et al. Effect of benzoic acid on metabolic fluxes in yeasts: a continuous-culture study on the regulation of respiration and alcoholic fermentation. Yeast. 1992;8(7):501-17. https://doi.org/10.1002/yea.32008 0703.

47. Vögtle, F.-N. et al. (2011) 'Mitochondrial protein turnover: role of the precursor intermediate peptidase Oct1 in protein stabilization.', Molecular biology of the cell. American Society for Cell Biology, 22(13), pp. 2135-2143. https://doi.org/10.1091/mbc.e11-02-0169.

48. Vuoristo, K. S. et al. (2015) 'Metabolic engineering of the mixed-acid fermentation pathway of Escherichia coli for anaerobic production of glutamate and itaconate., AMB Express. Springer, 5(1), p. 61. https://doi. org/10.1186/s13568-015-0147-y.

49. Warnecke T, Gill RT. Organic acid toxicity, tolerance, and production in Escherichia coli biorefining applications. Microbial Cell Factories BioMed Central. 2005;4:25. https://doi.org/10.1186/1475-2859-4-25.

50. Weusthuis RA, et al. Microbial production of bulk chemicals: development of anaerobic processes. Trends Biotechnol. 2011;29(4):153-8. https ://doi.org/10.1016/j.tibtech.2010.12.007.

51. Wilbanks, B. and Trinh, C. T. (2017)'Comprehensive characterization of toxicity of fermentative metabolites on microbial growth', Biotechno/ogy for Biofuels. BioMed Central, 10(262). https://doi.org/10.1186/s1306 8-017-0952-4.

52. Wolfe AJ.'The acetate switch', microbiology and Molecular biology reviews: mMBR. Am Soc Microbiol. 2005;69(1):12-50. https://doi. org/10.1128/MMBR.69.1.12-50.2005.

53. Yin, J. et al. (2007) 'Select what you need: a comparative evaluation of the advantages and limitations of frequently used expression systems for foreign genes.', Journal of biotechnology, 127(3), pp. 335-47. https://doi. org/10.1016/j.jbiotec.2006.07.012.

54. Yoshida, A. et al. (2005)'Enhanced hydrogen production from formic acid by formate hydrogen lyase-overexpressing Escherichia coli strains.', Applied and environmental microbiology. American Society for Microbiology, $71(11)$, pp. 6762-8. https://doi.org/10.1128/aem.71.11.6762-6768.2005.

55. Yukawa, H. et al. (2007) 'Manipulation of formate hydrogen lyase system in E. coli for increase its hydrogen generation capacity.', Jpn. Kokai Tokkyo Koho.

56. Zhu J, et al. Microbial host selection affects intracellular localization and activity of alcohol-Oacetyltransferase. Microb Cell Fact. 2015;14(1):1-10. https://doi.org/10.1186/s12934-015-0221-9.

57. Zinoni F, et al. Regulation of the synthesis of hydrogenase (formate hydrogen-lyase linked) of E. coli. Arch Microbiol. 1984;139(4):299-304. https://doi.org/10.1007/BF00408370.

\section{Publisher's Note}

Springer Nature remains neutral with regard to jurisdictional claims in published maps and institutional affiliations.

\footnotetext{
Ready to submit your research? Choose BMC and benefit from:

- fast, convenient online submission

- thorough peer review by experienced researchers in your field

- rapid publication on acceptance

- support for research data, including large and complex data types

- gold Open Access which fosters wider collaboration and increased citations

- maximum visibility for your research: over 100M website views per year
}

At BMC, research is always in progress.

Learn more biomedcentral.com/submissions 